\title{
Predictors of mortality in patients with Eisenmenger syndrome and admission to the lung transplantation waiting list
}

\author{
G. Callegari'1, A.M. D'Armini2, P. Baiardi33, M. Viganò2, C. Fracchia1
}

ABSTRACT: Predictors of mortality in patients with Eisenmenger syndrome and admission to the lung transplantation waiting list. G. Callegari, A.M. D'Armini, P. Baiardi, M. Viganò, C. Fracchia.

Background. Patients with Eisenmenger Syndrome (ES) have very severe irreversible pulmonary hypertension but the criteria for admitting such patients to a lung transplantation waiting list (LTWL) is not clear. Indeed it has been demonstrated that the natural survival of patients with ES is better than the survival achieved through lung transplantation: it follows that no guidelines are available for these patients' admission to an LTWL.

The aim of our study was to identify possible predictors of mortality in ES patients in order to reserve admission to the LTWL solely for those patients who would otherwise have the lowest probability of survival.

Methods. Since 1991, 57 patients with ES from our rehabilitative centre were admitted to the LTWL of the Division of Cardiac Surgery at San Matteo Hospital, University of Pavia. At the time of the retrospective analysis, patients were divided into a group of non-transplanted survivors ( 27 patients $-47 \%$ of the total) and a group who had died prior to transplantation (16 patients $-28 \%$ of the total). The 14 transplanted patients ( $25 \%$ of the total) were not considered in the statistical analysis, considering transplantation as an "external event".

Unpaired $t$ tests were used to compare the following factors in the survivors and in those who died: sex, "complexity" of the congenital heart disease underlying the ES, previous cardiac surgery, arterial blood gases, pulmonary function and hemodynamic parameters. Moreover, a stepwise discriminant analysis was performed in order to define a possible set of prognostic factors.

Results. $\mathrm{PaCO}_{2}$ was higher in those who subsequently died $(36.15 \pm 7.42 \mathrm{mmHg}$ ) compared with those who survived $(32.5 \pm 5.33 \mathrm{mmHg}$ ), although this difference did not reach a statistical significance $(p=0.08)$. Discriminant analysis defined a model in which a) complexity of the congenital heart disease, b) sex (male) and c) cardiac output were predictive of a higher risk of mortality.

Conclusions. This new knowledge can be used in the decision of admission to LTWL in ES patients.

Monaldi Arch Chest Dis 2004; 61: 4, 199-202.

Keywords: Eisenmenger syndrome, mortality, lung transplantation.

I Salvatore Maugeri Foundation IRCCS, Pulmonary Division, Scientific Institute of Montescano (Pavia).

2 Division of Cardiac Surgery, San Matteo Hospital IRCCS, University of Pavia, Pavia.

3 Salvatore Maugeri Foundation IRCCS, Medical Statistics, Scientific Institute of Pavia. Italy.

Correspondence: Dr Giovanna Callegari; Pulmonary Division; Salvatore Maugeri Foundation IRCCS; Scientific Institute of Montescano; 27040 Montescano (PV); Italy; e-mail: gcallegari@fsm.it

\section{Introduction}

Eisenmenger Syndrome (ES) occurs as a result of diverse congenital cardiac anomalies and is manifested by severe irreversible pulmonary artery hypertension with dilatation of the central pulmonary arteries and reversal of a previous left-toright atrial, ventricular or aortopulmonary shunt. The resultant right-to-left or bi-directional shunt leads to clinical cyanosis and the secondary manifestation of hypoxemia [1].

Over the past 20 to 30 years, major advances have been made in the diagnosis and treatment of congenital heart diseases in children. As a result, many children with such diseases now survive to adulthood $[2,3]$.

Heart-lung and lung transplantations (LT) have been proposed as "definitive" therapy for patients with ES $[4,5]$; nevertheless recent data suggests that there is an increased risk of death after LT in this population $[6,7]$. In a previous study, considering a 6-month time limit on the waiting list, we have demonstrated hemodynamic risk for ES patients [8]; more recently we have demonstrated that patients with ES have a longer survival before LT than after this procedure [9].

Accurate survival information is important in order to select patients who are in the greatest need of transplantation. The mortality rate of patients with ES has been correlated with their age, functional class, arrhythmia and electrocardiogram index of right ventricular hypertrophy [10].

The aim of our retrospective study was to evaluate prognostic factors for mortality in ES patients, in particular sex, "complexity" of the congenital heart disease causing ES, previous cardiac surgery, arterial blood gases, pulmonary function and hemodynamic parameters, in order to reserve 
admission to a lung transplantation waiting list (LTWL) only to those patients with an otherwise lower probability of survival.

\section{Materials and Methods}

\section{Patients}

The study population was formed of $57 \mathrm{ES}$ patients assessed at our Centre prior to their admission to the LTWL of the Division of Cardiac Surgery Division at San Matteo Hospital, University of Pavia, between 1992 and 2002.

At the time of analysis, patients were divided into a group of non-transplanted survivors (27 patients $-47 \%$ of the total) and a group who had died before transplantation (16 patients $-28 \%$ of the total). The 14 transplanted patients (25\% of the total) were not considered in the statistical analysis, considering transplantation as an "external event".

\section{Hemodynamic measurements}

All patients underwent right heart catheterisation with a No. $7 \mathrm{~F}$ balloon flotation pulmonary artery catheter positioned through a No. 9F Cordis introducer sheath in the right internal jugular vein at the time of the screening for the patients' inclusion in the LTWL.

\section{Pulmonary function tests}

Dynamic and static lung volumes were evaluated by plethysmography with the patients in the seated posture. An automated analyzer was used to measure gases in blood samples from the radial artery.

\section{Statistics}

Unpaired $t$ tests were used to compare the following possible prognostic factors in the patients who survived and in those who subsequently died: sex, "complexity" of the congenital heart disease causing the ES: congenital heart diseases were simple malformations such as atrial septal defect (ASD); ventricular septal defect (VSD), patent ductus arteriosus (PDA); atrio-ventricular septal defetc (AVSD) and other complex ones including uni-ventricular heart, uni-atrial heart, transposition of the great arteries, truncus arteriosus, tricuspid or pulmonary

Table 1. - Characteristics of patients in the study

\begin{tabular}{lcc}
\hline & ALIVE & DEAD \\
\hline $\mathrm{N}$ & 27 & 16 \\
Age of inclusion in LTWL & $36 \pm 8$ & $33 \pm 11$ \\
Months in LTWL & $57 \pm 20$ & $11 \pm 9$ \\
Current age /age at death & $40 \pm 9$ & $34 \pm 11$ \\
Weight $(\mathrm{Kg})$ & $52 \pm 11$ & $56 \pm 14$ \\
Height $(\mathrm{Cm})$ & $160 \pm 10$ & $165 \pm 10$ \\
\hline
\end{tabular}

atresia; other parameters were previous cardiac surgery, arterial blood gases, pulmonary function and hemodynamic parameters. Moreover, a stepwise discriminant analysis was performed in order to define a possible set of prognostic factors.

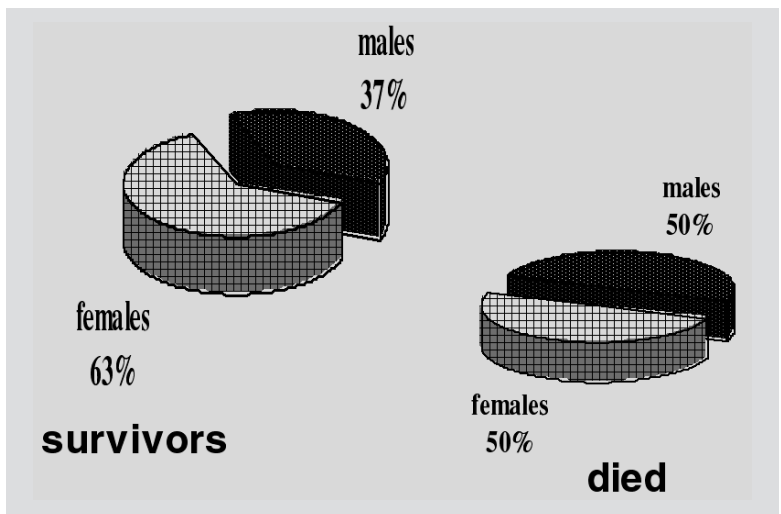

Fig. 1. - Gender of patients.

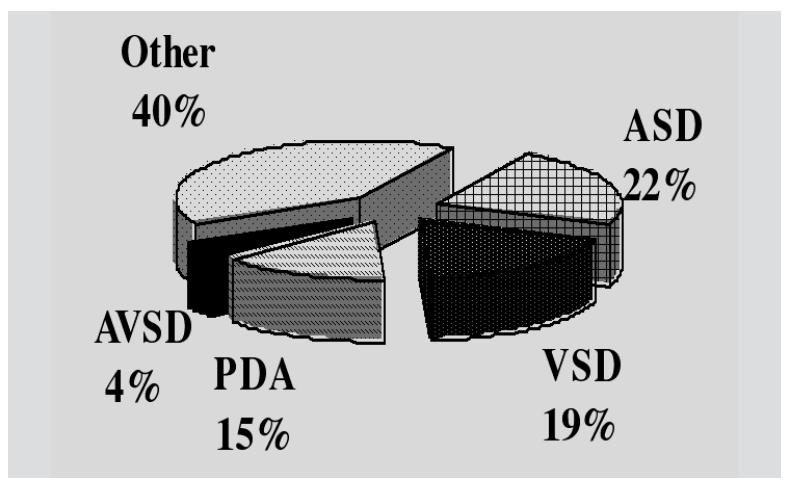

Fig. 2. - Congenital heart diseases of survivors (see text for abbreviations).

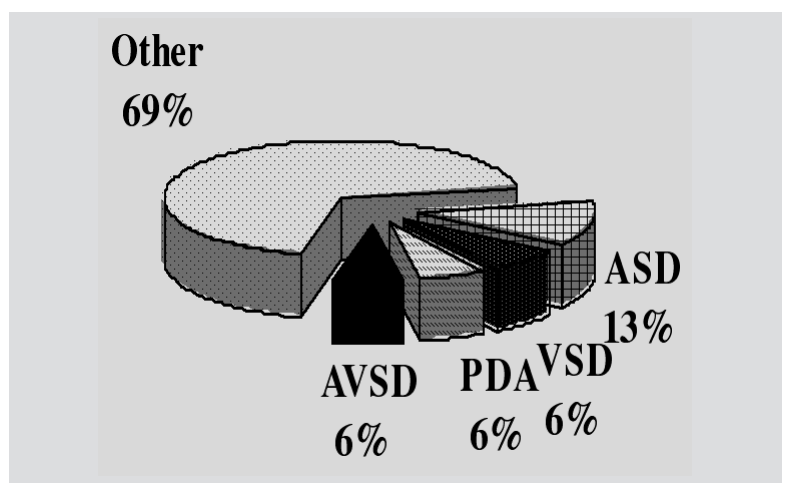

Fig. 3. - Congenital heart diseases of patients who died (see text for abbreviations).

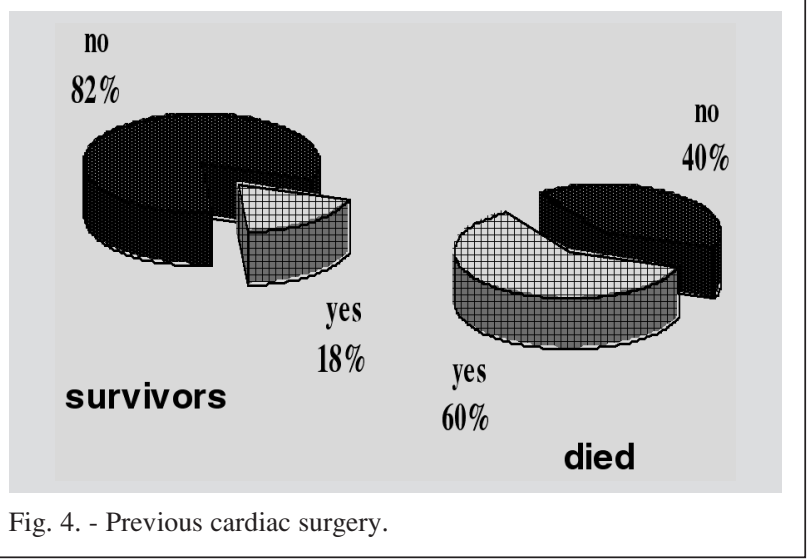




\section{Results}

Of the 43 patients, $27(47 \%)$ are alive after a waiting time of $57 \pm 20$ months and $16(28 \%)$ died after a waiting time of $11 \pm 9$ months.

The characteristics of the survivors and those who died are reported in table 1 and in figure 1. Survivors are $40 \pm 9$ years old while the patients who died were $34 \pm 11$ years old. Of the survivors $63 \%$ are female; in the group who died females were $50 \%$.

Figures 2 and 3 show that congenital heart diseases in the survivors are previously "simple" defect while in the patients who died the most part of congenital heart diseases were "complex". Figure 4 shows that $18 \%$ of survivors underwent previous cardiac surgery, while in the patients who died the percentage of previous cardiac surgery was $60 \%$.

Tables 2 and 3 list pulmonary functions, arterial blood gases and hemodynamic measurements in the two groups.

Table 2. - Arterial blood gases and pulmonary function tests

\begin{tabular}{lccc}
\hline & ALIVE & DEAD & p \\
\hline $\mathrm{FEV}_{1} \%$ pred & $66 \pm 19$ & $64 \pm 16$ & $\mathrm{~ns}$ \\
$\mathrm{FVC} \%$ pred & $71 \pm 18$ & $71 \pm 20$ & $\mathrm{~ns}$ \\
$\mathrm{PaO}_{2} \mathrm{mmHg}$ & $48.48 \pm 14.68$ & $54.06 \pm 19.63$ & $\mathrm{~ns}$ \\
$\mathrm{PaCO}_{2} \mathrm{mmHg}$ & $36.15 \pm 7.42$ & $32.5 \pm 5.33$ & 0.08 \\
$\mathrm{Sat} \%$ & $81 \pm 11$ & $85 \pm 10$ & $\mathrm{~ns}$ \\
\hline
\end{tabular}

$\mathrm{FEV}_{1}$ and $\mathrm{FVC}$ are expressed as \% of predicted

$\mathrm{PaO} 2$ and $\mathrm{PaO} 2$ are expressed in $\mathrm{mmHg}$

Results are expressed as mean \pm standard deviation

Table 3. - Hemodynamic profile of alive and dead patients

\begin{tabular}{lrcl}
\hline & ALIVE & DEAD & p \\
\hline PAS & $116 \pm 28$ & $112 \pm 38$ & $\mathrm{~ns}$ \\
PAM & $79 \pm 21$ & $75 \pm 25$ & $\mathrm{~ns}$ \\
PAD & $56 \pm 18$ & $54 \pm 20$ & $\mathrm{~ns}$ \\
PCWP & $13 \pm 11$ & $15 \pm 11$ & $\mathrm{~ns}$ \\
PAM-PCWP & $63 \pm 18$ & $61 \pm 29$ & $\mathrm{~ns}$ \\
CO & $4.7 \pm 1.6$ & $4 \pm 1.5$ & $\mathrm{~ns}$ \\
CI & $3.1 \pm 1.1$ & $2.6 \pm 1$ & $\mathrm{~ns}$ \\
PVR & $1138 \pm 457$ & $1700 \pm 1555$ & $\mathrm{~ns}$ \\
\hline
\end{tabular}

Results are expressed as mean \pm standard deviation

PAS: pulmonary arterial systolic pressure

PAM: pulmonary arterial mean pressure

PAD: pulmonary arterial diastolic pressure

PCWP: pulmonary capillary wedge pressure

CO: cardiac output

CI: cardiac index

PVR: pulmonary vascular resistance

Pressures are expressed in $\mathrm{mmHg}$; $\mathrm{CO}$ in $1 / \mathrm{m} ; \mathrm{CI} \mathrm{l} / \mathrm{m} / \mathrm{mq}$

body surface; PVR in dynes* $\mathrm{sec}^{*} \mathrm{~cm}^{-5}$

The unpaired $t$ tests comparing sex, "complexity" of the congenital heart disease causing the ES, previous cardiac surgery, arterial blood gases, pulmonary function and hemodynamic parameters in the survivors and the patients who died showed that only $\mathrm{PaCO}_{2}$ was nearly statistically different $(\mathrm{p}=0.08)$ between patients who died $(36.15 \pm 7.42 \mathrm{mmHg})$ and those who survived $(32.5 \pm 5.33 \mathrm{mmHg})$.

Discriminant analysis defined a model in which a) complexity of the congenital heart disease, b) sex (male) and c) cardiac output predicted a higher risk of mortality.

\section{Discussion}

Our retrospective study is limited by the small number of patients but adds new knowledge for the decision as to whether or not to admit a patient with ES to a LTWL, with the awareness that this management is not always advantageous in this particular group of patients.

LT has been proposed as "definitive" therapy for patients with $\operatorname{ES}[4,5]$. However, recent data suggests that there is an increased risk of death after LT in this group [6]. Furthermore we have recently demonstrated that patients with ES have a an increased survival rate before LT than after it [9] when considering all patients; on the other hand we have also demonstrated that using a 6- months cut off in the LTWL, some hemodynamic parameters are important [8]. A recent study [7] concluded that LT is the best treatment option for patients with end-stage lung disease, observing that LT conferred a survival advantage to all patients in the study with the exception of those with congenital heart disease. Indeed patients with ES can survive into their seventh decade with good medical care and protection [11].

Nevertheless there is a large variation in the life expectancy of patients with ES: some undergo clinical deterioration and sudden death so accurate survival information is important in order to select patients who are in the greatest need of LT. The value of the patient's gender, "complexity" of the congenital heart disease causing the ES, previous cardiac surgery, arterial blood gases, pulmonary function and hemodynamic data as predictors of mortality is not known. The aim of our retrospective study was to investigate the significance of the aforementioned parameters as prognostic factors for mortality in ES patients in order to reserve admission to LTWL only for those patients with the lowest probability of survival without this intervention.

The unpaired $t$ tests comparing sex, "complexity" of the congenital heart disease causing ES, previous cardiac surgery, arterial blood gases, pulmonary function and hemodynamic parameters in the groups of survivors and the patients who died showed that only $\mathrm{PaCO}_{2}$ was nearly significantly different $(\mathrm{p}=0.08)$ while $\mathrm{PaO}_{2}$ was not significantly different between the two groups: the relevance of this result is not clear, but is interesting that $\mathrm{PaO}_{2}$ was not significantly different between the patients who died and those who are still alive; in fact the hypoxaemia resulting from a right-to-left or bidirectional shunt is one of the most characteristic features of ES patients [1]. The pulmonary function was not significantly different between the survivors and in those who died, in accordance with the fact that spirometric compromise is not the main respiratory problem of these patients. 
Hemodynamic parameters were not different between the two groups: this result is surprising if compared to a previous paper [8], but demonstrates, in this case, that hemodynamic compromission is the same in the survivors and in those who died, because pulmonary hypertension is well established early in the lives of such patients.

Previous cardiac surgery did not emerge as a statistically significant factor: in fact, pulmonary hypertension is often already present when cardiac surgery is carried out, and the repair of any major cardiac abnormalities does not relieve the hypertension.

Unfortunately these results are not helpful in the selection of patients who are in the greatest need of transplantation; nevertheless our study adds new knowledge for the decision of whether or not to admit a patient with ES to a LTWL. In fact, as concerns the discriminant analysis, the complexity of the congenital heart disease resulted to be predictive of a higher risk of mortality in association with sex (male) and cardiac output. Complex anatomy associated with young age has just been demonstrated as being associated with increased mortality (10): the peculiarity of our result is that discriminant analysis described a model in which complexity of the congenital heart disease resulted in a predictably higher risk of death in association with sex (male) and cardiac output.

Complex congenital disease was present in $69 \%$ of patients who died whilste only in $40 \%$ of survivors; of patients who died before being transplanted, $50 \%$ were male and $50 \%$ female, whereas $63 \%$ of the survivors are female. As concerns cardiac output, this was $4.7 \pm 1.6 \mathrm{l} / \mathrm{m}$ in the survivors and $4.0 \pm 1.5 \mathrm{l} / \mathrm{m}$ in the group of patients who died.

To conclude complexity of the congenital heart disease, sex (male) and cardiac output could be considered to be predictive of major mortality in a population of patients with ES.

The small number of patients in this study retrospective study limits the robustness of our conclu- sion; nevertheless, in the absence of other significant prognostic factors for mortality, this new knowledge can be now used in the decision of whether or not to admit a patient with ES to an LTWL with the awareness that this management is not always advantageous in this particular population of patients.

\section{References}

1. Wood P. The Eisenmenger syndrome or pulmonary hypertension with reversed central shunt. Br Med J 1958; 2: 701-709, 755-62.

2. Brickner ME, Hillis LD and Lange R. Congenital heart disease in adults. First of two parts. N Engl J Med 2000; 342: 256-262.

3. Brickner ME, Hillis LD and Lange R. Congenital heart disease in adults. Second of two parts. $N$ Engl J Med 2000; 342: 334-342.

4. Reitz BA, Wallwork J, Hunt SA et al. Heart-lung transplantation: successful therapy for patients with pulmonary vascular disease. N Engl J Med 1982; 306: 557-64.

5. Bando K, Armitage JM, Paradis IL et al. Indications for and results of single, bilateral and heart-lung transplantation for pulmonary hypertension. J Thorac Cardiovas Surg 1994; 108: 1056-65.

6. Hosenpud JD, Bennet LE, Keck BM et al. The Registry of the International Society for Heart and Lung Transplantation: Fifteenth Official Report - 1998.

7. De Meester J, Smits JMA, Persijn GG et al. Listing for lung transplantation: life expectancy and transplant effect, stratified by type of end stage lung disease, the Eurotransplant experience. J Heart Lung Transplant 2001; 20: 518-524.

8. D'Armini AM, Callegari G, Vitulo P et al. Risk factors for early death in patients awaiting heart-lung or lung transplantation. Transplantation 1998; 66: 123-127.

9. Callegari G, D’Armini AM, Viganò $\mathrm{M}$ et al. Lung transplantation: the new point of view of an Italian centre. Monaldi Arch Dis 2000; 55 (4): 283-286.

10. Cantor WJ, Harrison DA, Moussadji JS. Determinants of survival and length of survival in adults with Eisenmenger syndrome. Am J Cardiol 1999; 84: 677-81.

11. Daliento L, Somerville J, Presbitero P et al. Eisenmenger syndrome. Factors relating to deterioration and death. Eur Heart J 1998; 19: 1845-1855.

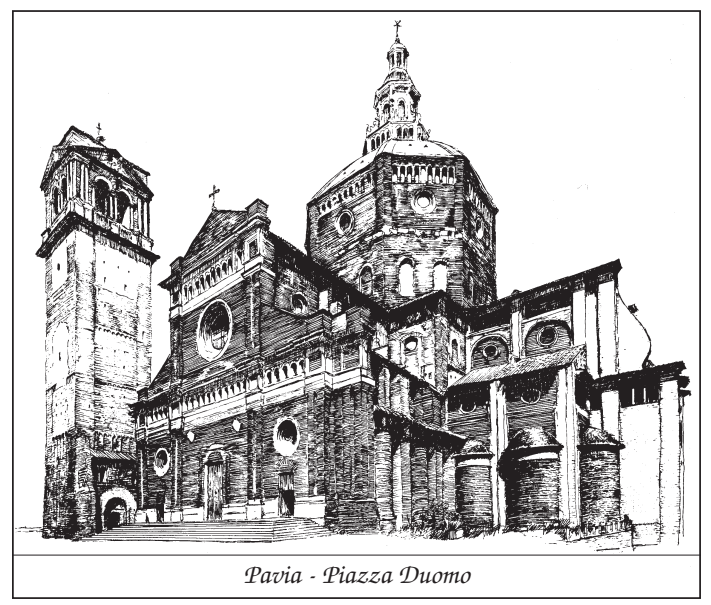

